\title{
Content analysis for Agricultural Records of the United Kingdom, AD 200 to 1977: a study of frequency in human records concerning climate phenomenon
}

\section{H. Holt}

Department of Geography and Geology, University of Southern Mississippi, Hattiesburg, MS 39406, USA

Received: 17 July 2011 - Accepted: 22 July 2011 - Published: 2 August 2011

Correspondence to: D. H. Holt (david.h.holt@usm.edu)

Published by Copernicus Publications on behalf of the European Geosciences Union.
$7,2555-2577,2011$

Content analysis for Agricultural Records

D. H. Holt

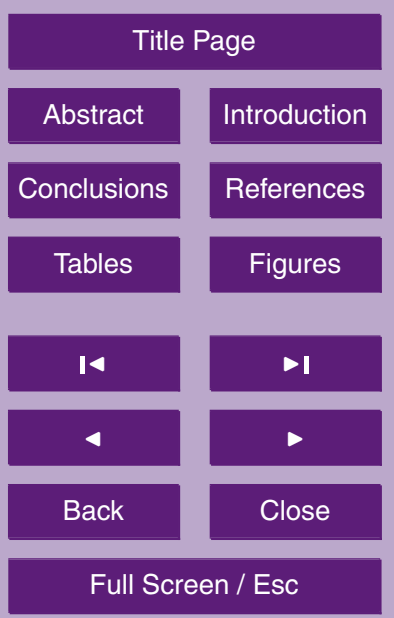

Printer-friendly Version

Interactive Discussion 


\section{Abstract}

A content analysis has been completed on a text from the UK that has gathered agricultural and climate data from the years AD 220 to 1977 from 100s of sources. The content analysis coded all references to climate and agriculture to ascertain which climate 5 events were recorded and which were not. This study addressed the question: is there bias in human records of climate? This evaluated the continuous record (AD 16541977), discontinous record (AD220-1653), the whole record (AD 220-1977), the Little Climate Optimum (AD 850-1250) and the Little Ice Age (AD 1450-1880). This study shows that there is no significant variation in any of these periods in frequency oc-

\section{changes in climate, but they are recording weather phenomenon as it occurs.}

\section{Introduction}

Humans have been interested in and recording climate phenomena for millennia. Global climate change is a great concern to humans but scientifically-derived meteorological data only cover the last $\sim 150$ years. This is problematic in discourses about global change as the records are too brief to reveal long trends. Before meteorologically derived data, one has to infer climate through proxies or historical documents. There are human records of past climates in various forms including military records, paintings, diaries, agricultural reports, poetry, books, newspapers, or ship logs. The historian, by definition, studies and interprets written sources, where there are good sources the history can be detailed and quite accurate. In turn, where the sources are poor the history cannot be much better (Reece, 1999).

The use of historical documentation is essential in understanding human behavior in the past, especially the distant past. However, with the distant past, climate history must be central in historical reconstruction or suffer a woefully limited view of the past (Wigley et al., 1981). Changes in climate, including specific weather phenomenon, has
$7,2555-2577,2011$

Content analysis for Agricultural Records

D. H. Holt
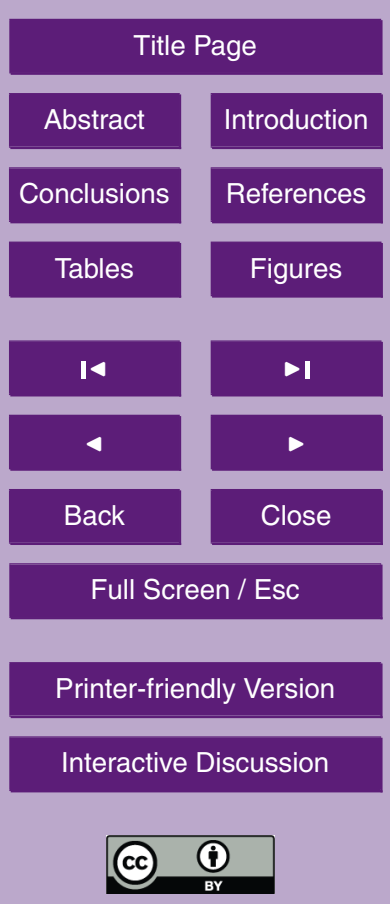
and continues to affect human behavior and is often ignored in historical compilations. It is necessary for the historian to "retrodict" a rational reconstruction of history and compare it to actuality (Parry, 1981). It is through our understanding of the present that the past is better understood. Historical documents can then be useful in the discourse

\section{Climate and written sources}

As early as $3000 \mathrm{BC}$, historical documents recorded information about climate, either by direct reference or by inference. By looking directly to the written word, many different aspects of past environments can be extracted from temperature to sunspot activity.

10 The question is what elements of climate did the authors of these historical documents find important enough to record? Is there bias toward extreme or "bad" weather when events are recorded?

Various historical records "hide" climate data, not only in agricultural accounts, but in seemingly climate-irrelevant accounts as well. Tucked into letters from the Czarina, 15 Catherine the Great, to the peasant, Ménétra, are casual comments concerning food production or snowfall and the like that can be compiled into relatively detailed climate reconstructions (Catherine, 1955; Ménétra, 1984). An accountant's record book from a Kentish Estate contains proxy data concerning crop prices, flood damages, or times of famine, not just a ledger of expenditures of a large English estate (Toke and 20 Lodge, 1927). Ancient texts yield information in the form of poetry, as with Ovid's Metamorphoses, or military stratagem may provide insight about drought in Thucydides' Peloponnesian War.

In an effort to attempt to assess if historical documents will record climate change, it is necessary to evaluate documents. Agricultural records, for example, are valuable for their reflection of production, flora variety, and associated changes over time. This is evident in the book, Times of Feast, Times of Famine; the various French winery records mirror times of drought and times of prosperity as based on harvest dates

Content analysis for Agricultural Records

D. H. Holt

\section{Title Page}

Abstract Introduction

Conclusions References

Tables Figures

\begin{tabular}{|c|c|}
\hline I4 & - \\
\hline Back & Close \\
\hline Full Screen / Esc \\
\hline
\end{tabular}

Printer-friendly Version

Interactive Discussion

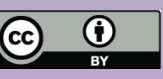


for grapes (Le Roy Ladurie, 1988). The vineyards were of great importance and their records are not only useful they are long and continuous and show a direct relationship between vineyard harvest dates and climate variability. Other food sources can be used as proxies as with Ogilivie and Jonsdottir's study on fish hauls and sea ice extent 5 from documents in Iceland over the 18th and 19th centuries (Ogilvie and Jonsdottir, 2000). This study gives a proxy of sea surface temperature and infers other climate variability from documents that were not necessarily intended as a climate proxy.

The use of historic documents to reconstruct climate histories is validated through comparing the written documents to instrumental data and paleoclimate proxies (Fren10 zel et al., 1992; Dobrovolný et al., 2010; Ogilvie, 2010; Holt, 2011). Societies are vulnerable to natural hazards and climate change and often document these occurrences (Frenzel et al., 1992; Pfister, 2010). A few studies (Brázdil et al., 2010a; Zorita et al., 2010) have looked at historic climatology over the past 500 years in Europe to compare both the instrumental and paleoclimate record to test consistencies between these proxies. There seems to be a good alignment of historical climatology and proxies. Further, efforts are being made to create a grid of document data for all of Europe for an historical climatological reconstruction that can be compared to proxy and instrumental data (Dobrovolný et al., 2010). This paper is interested in the consistency of these recorded occurrences and if they change over time.

A good example of a broad-based, comprehensive listing of production that holds many climate references in England is a document entitled, Agricultural Records. It was initially compiled by Thomas H. Baker in 1883, updated by John Stratton in 1969, with the latest version compiled by Ralph Whitlock in 1978 (Stratton and Brown, 1978). The purpose of the book is to provide a running record of the agricultural and climate changes in England from as many sources as possible. The authors used everything from meteorological records to ancient legend and anecdotal sources. Agricultural Records is an amalgamation of many sources from AD 220 to 1977 attempting to form an accurate agricultural and climatic history of England.
7, 2555-2577, 2011

\section{Content analysis for} Agricultural Records

D. H. Holt

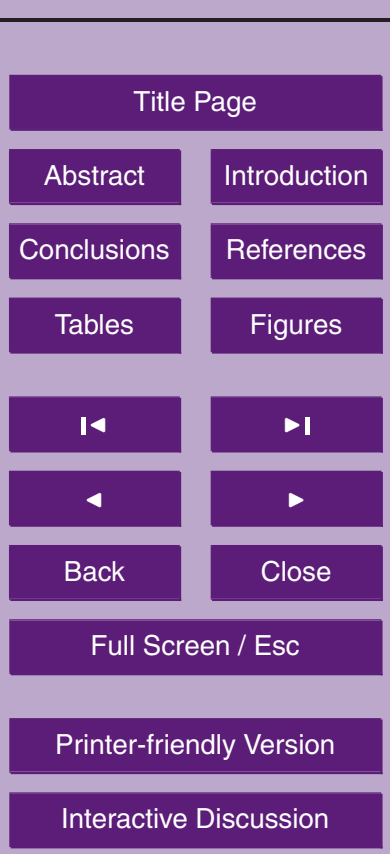


Agricultural Records provides excellent insight into the past climates of England and, more importantly, what climate events were deemed worth while to document. This document might yield insight into the schema of documenting weather before meteorological data. But do these records document all the environmental characteristics of the 5 region or just some of them? What did the authors consider worthy of documenting? How can these documents be analyzed for content so long after they were written? Analysis of this document is directly related to the validity of historical documents as climate proxy indicators. A means to approach these types of quandaries is through a methodology found in rhetorical communication called "Content Analysis".

\section{Content analysis of Agricultural Records}

Content analysis is a systematic approach of partitioning word usage in large data sets used in the field of communication (George, 1954; Reinard, 1998; Hodson, 1999). The main element of this approach is to quantify the occurrence of a particular event or comment statistically to establish its frequency of use. For example, if the question 15 was raised, "do women appear in historical documents in Western Europe between the years $400 \mathrm{BC}$ to AD 800 ?" The task of reading every piece of literature over this period and quantifying every occurrence is not feasible. The methodology of a content analysis allows a review of a representative percentage of all literature to find the frequency of female references and assume it is representative of the whole. Ideally,

a content analysis would include all documents, but this is not always possible. The benefit of this technique is that it attempts to remove the researcher from the research and gives a relatively unbiased assessment of the topic being evaluated. This is especially important when the question is an abstract concept such as a "violent act" or an "insulting comment" or, in Agricultural Records, "cold" or "pleasant" (Reinard, 1998).

The way the researcher is "removed" is through a series of steps that are necessary to accomplishing a proper content analysis. First, the area of communication is to be defined, such as the Agricultural Records of England from AD 220 to 1977. Second,
7, 2555-2577, 2011

Content analysis for Agricultural Records

D. H. Holt

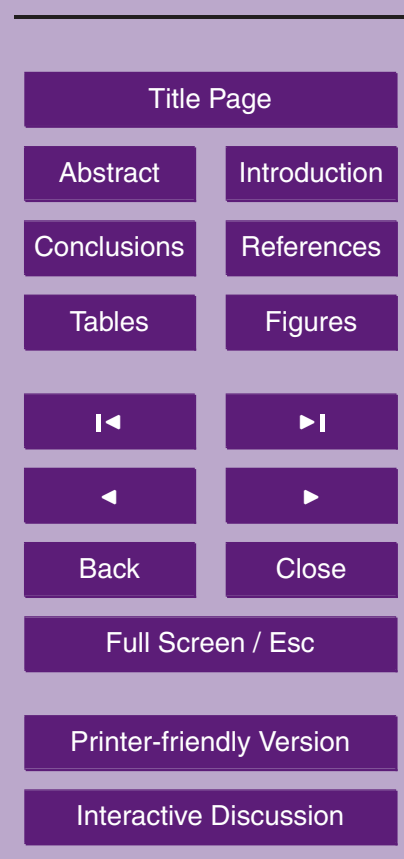

Interactive Discussion

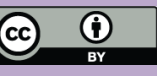


the semantics must be categorized in a logical manner to permit a coding system of the word usage to be developed. This must be selected in a fashion that will allow for all possible units to be covered with a minimal of units falling into an "other" or "miscellaneous" category. Next, the sample size must be defined and be large enough 5 to cover the entire topic. This can be an arbitrary definition, but it needs to attempt to cover the majority of the documents. Logically, the more complete the coverage, the more accurate the content analysis. The bulk of the analysis falls in the next category - coding the message content. This must be reproducible by independent researchers with a margin of error under $5 \%$ using only the coding system (George, 1954). The 10 Agricultural Records intercodal dependency was under $2 \%$ margin of error, meaning independent researchers who performed the same analysis on the 1758 year period using the same text and coding system and was less than $2 \%$ different in their results than this study. Being that the intercodal dependency was below the $5 \%$ required, the next step is to analyze the data either numerically or graphically. The final step is to interpret the results with the stern warning that a content analysis cannot give causeeffect conclusions (George, 1954). In this study the interpretation had to compensate for discontinuity in Agricultural Records, so analysis will evaluate the whole record (AD 220-1977), the discontinuous record (AD 220-1653), and the continuous record (AD 1654-1977). It will also evaluate the Little Climate Optimum (LCO) (950-1250) and the Little Ice Age (LIA) (1450-1880) as these periods are believed to be warmer and colder respectively and if bias does exit, perhaps it will be revealed in these periods.

\section{Materials and methods}

This study compiled data from an historical document of the UK to find out which elements of climate are recorded over time. The content analysis of Agricultural Records followed standard communication techniques set out by George (1954). The text was read and evaluated to establish a coding system to include as many topics as possible. While the original intention was to code the text purely quantitatively, a few references
7, 2555-2577, 2011

Content analysis for Agricultural Records

D. H. Holt

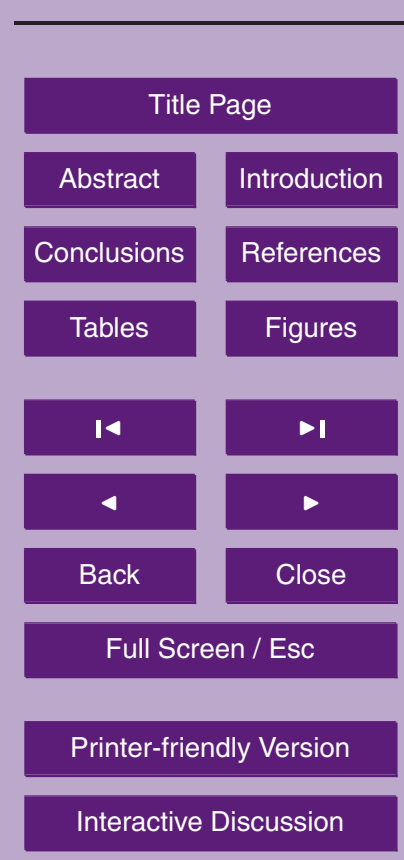

Interactive Discussion

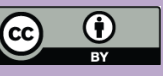


necessitated qualitative coding. It was the hope to build a coding system that would match this and any text with the greatest possible consistency, so that other coders would produce the exact same numbers. Being a text that is compiling historical documents, it does change its semantics in describing similar events such as a flood being 5 des described as a flow over banks or a mild weather described as fine or brilliant.

The focus of the content analysis was on climate and agricultural references. The use of Agricultural Records is justifiable as it is an edited collection of climate and agricultural that is attempting to give a comprehensive overview of crops and livestock with any climate data available. The text uses a dating system with a synopsis of that 10 year's climate and agricultural productivity with commodity prices. Upon examination of the text, it appeared that a replicatable coding system could be developed to evaluate what climate data is being recorded and how it has changed over time.

\section{Content analysis - coding system}

Agricultural Records was examined from AD 220 to 1977 (every year recorded was 15 quantified giving a margin of error of $0 \%$ ). The coding system of this 1758-year period was divided into five principle categories - Human, Phenomena, Agriculture, Climate, and Season. Human category was broken into two subcategories of Famine and Plague Human. Phenomena category was broken into five subcategories of Phenomenon (Other), Tide, Earthquake, Frozen Rivers and Flood. The Agriculture 20 category was subdivided into six categories of Good and Bad Harvests, Good and Bad Livestock, Drought, and Animal Plague. The Climate category was subdivided into fourteen categories of Climate Recorded, Cool, Cloudy, Mild-Warm, Snow-Ice, Dry, Hot, Sunny, Fog, Cold-Frost, Harsh Winter, Late Spring, Wet-Rainy, and StormsWindy. And the Season category was subdivided into five categories of Year, Winter,
$7,2555-2577,2011$

Content analysis for Agricultural Records

D. H. Holt

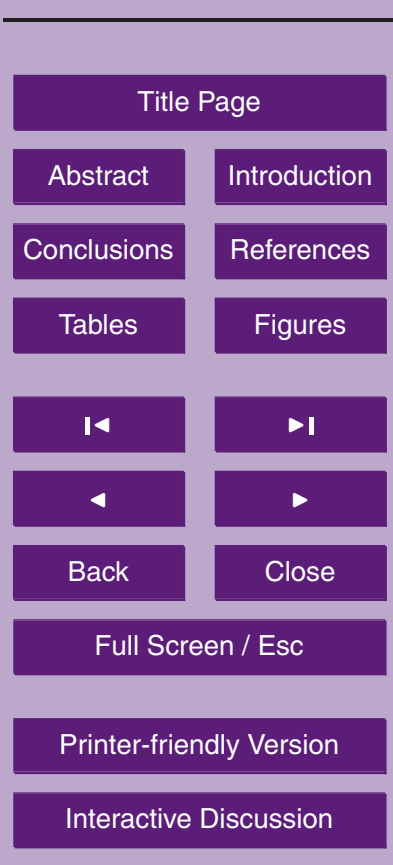

Interactive Discussion ered all references to climate, agriculture, or human ailments. The records that do not fall into the coding scheme are the occurrences of historical markers such as books 
published, historical events, commodity prices, or discoveries. These items were discarded as irrelevant to the study at hand. Every other record was quantified inside the parameters of the coding scheme.

\subsection{Definitions of the coding scheme}

\section{$5 \quad$ 5.1.1 Climate references}

A. Climate Recorded is the code reserved for meteorologically recorded precipitation or temperature amounts given in any sort of tangible increments. Rainfall records are of the earliest meteorologically recorded data starting in 1677 and temperature in 1750 in England.
B. Cool category is any reference to cool temperatures.

C. Cloudy is any cloudy or dull time due to cloud cover without precipitation.

D. Fog is any reference to foggy conditions.

E. Sunny is any reference to sunny or bright conditions.

F. Mild-Warm is any reference to mild or warm summers (not hot) or winters, which include terms such as fine and brilliant.

G. Dry is reserved for periods that are dry by name or times explained that have little to no rain.

$\mathrm{H}$. Hot is a reference to high summer temperatures or higher than normal winters.

I. Cold-Frost is the category reserved for cold periods, late or hard frosts, or periods of heavy snow. Snowstorms or blizzards would not code into this category.

J. Snow-lce is the category for snow, snow storms, freezing rain, blizzard, or ice, but not frozen rivers.
$7,2555-2577,2011$

Content analysis for Agricultural Records

D. H. Holt

\section{Title Page}

\section{Abstract}

Introduction

Conclusions

References

Tables

Figures

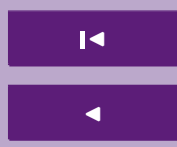

- I

Back

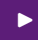

Close

Full Screen / Esc

Printer-friendly Version

Interactive Discussion

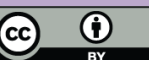


K. Wet-Rain category is for periods that are wetter than normal due to rain or dampness. Any non-storm event that is recorded is considered rain.

L. Storms-Windy classification requires the word storm by name. "There were heavy storms", "it was a very windy period", rainstorms or thunderstorms are included but mention of snowstorms and the like are coded with Snow-Ice.

M. Harsh Winter is the category for severe or harsh winter months.

N. Cold, Late Spring is the category for cold, late, or cool spring months.

\subsubsection{Phenomena}

A. Earthquakes is a category for recorded earthquakes.
B. Flood is a category for recorded floods.

C. Frozen Rivers is a specialized category for the recording of cold period where a major river froze to a significant degree as to denote recording.

D. Tide is a code reserved for natural phenomenon including gales and hurricanes that caused unusual tidal flow.

E. Phenomena is a category for any other atmospheric or weather phenomenon such as hail, tornadoes, auroras, or eclipses.

\subsubsection{Human references}

A. Plague Human is reserved for the mention of disease or plague that effects human beings. Such occurrences are under the name of Black Death, Sweating Sickness, or the like.

B. Famine is a time of scarcity or lack of food for humans or the loss of complete crops to the point of malnutrition.
$7,2555-2577,2011$

Content analysis for Agricultural Records

D. H. Holt

\section{Title Page}

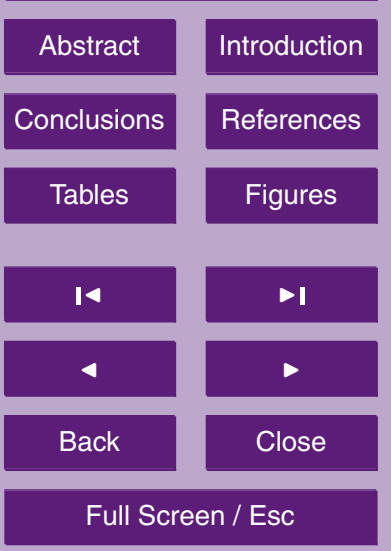

Printer-friendly Version

Interactive Discussion

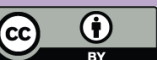




\subsubsection{Agriculture references}

A. Good Harvest is the reference reserved for times of abundant to average output. Both good and bad harvest can be quantified for the same year if there is record of a crop doing well and a crop doing poorly.

B. Bad Harvest is used for a crop that has under performed the intentions of the harvester.

C. Good Livestock is a favorable standing among herds or a noted increase in population among livestock.

D. Bad livestock is a listing that includes a drop in population or culling among grazing animals or a subsequent disease that lowers population.

E. Plague Animal is any listing of disease or a plague of any animal.

F. Drought is used for times of dry periods that are recorded as affecting the harvest directly or referred to by name.

\subsubsection{Seasonal references}

A. Year is defined as any reference that is made referring to the entire year. For example, dates that state a year of drought or a cold year would classify as year, but statements concerning only part of the year would be classified by the season.

B. Winter is defined by any reference to winter or an event that falls between $22 \mathrm{De}-$ cember and 21 March. This will classify events from the previous year between 22 and 31 December.

C. Spring is defined by any reference to spring or an event that falls between 22 March and 21 July.

Content analysis for Agricultural Records

D. H. Holt

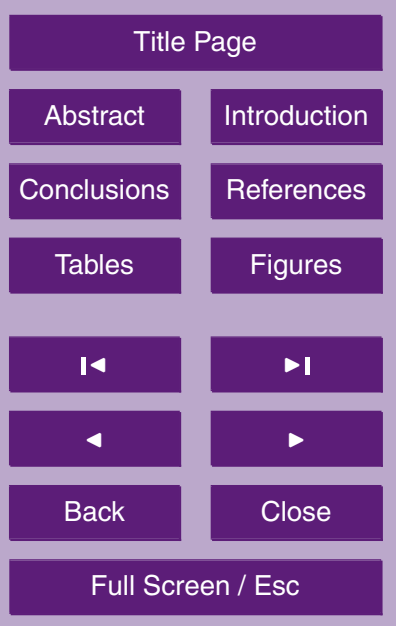

Printer-friendly Version

Interactive Discussion

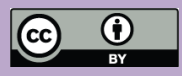


D. Summer is defined by any reference to summer or an event that falls between 22 July and 21 September.

E. Fall is defined by any reference to fall, autumn, or an event that falls between 22 September and 21 December.

\section{$5 \quad$ 5.1.6 Example of coding scheme}

If we use the entry for 1816, the "year without a summer", we can see how the coding system works. In 1815, there was a large volcanic eruption of Tambura that covered the Earth a blanket of sulfates that reflected solar energy and kept the earth dramatically cooler in the higher latitudes. There have been reconstructions of this event using proxies such as tree rings (Briffa et al., 1988) and ship logs (Chenoweth, 1996) as well as evidence from instrument data. Here is the reference from the book, Agricultural Records:

Wheat 78 s $6 \mathrm{~d}$ per quarter.
- A wet summer with a very poor harvest.

- A winter of storm, gales and floods. Spring was late and cold. Severe weather, with snow lying on ground, in mid-April.

- Summer and autumn were also cold and wet, with very little sunshine. The temperature for July and August was $4.8 \times$ below average, and the heavy rain was accompanied by strong winds. Quite a heavy snowfall in the eastern counties on 2 September, with severe frost in London and elsewhere.

- Harvest began late, in many districts not before the end of August. Wheat sprouted and was in poor condition. In the Midlands and North much corn was still in the fields in November.
$7,2555-2577,2011$

Content analysis for Agricultural Records

D. H. Holt
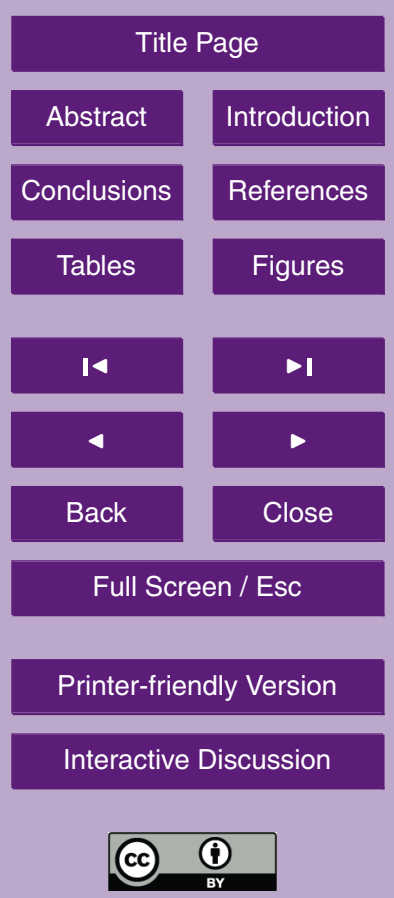
- Sheep-rot was prevalent; hay scarce; and much livestock was sold for lack of keep.

- One of the most disastrous harvests known.

- Much distress, and food riots.

5 The coding system would not code the commodity price listing as this is the main focus of book and not the focus of this study. All four seasons are recorded. The Climate category codes Cold Spring, Snow-lce, Cold-Frost, Cloudy, Storms-Windy, Wet-Rainy, and Climate Recorded. The Agricultural category codes Bad-Late Harvest, Bad Livestock, and Plague Animal. The Human category coded Famine and the Phenomena category coded Flood. The code, Cloudy, was qualified from the statement "very little sunshine". The code, Famine, was qualified from the statement "food riots" which implies food shortages.

\subsection{Success and failure in Agricultural Records}

If we examine the year of 1783 and the winter of 1783,1784 , we can find evidence 15 to significant flooding throughout Europe and what was called the "Great Dry Fog of 1783". The Great Dry Fog originated from an Icelandic volcanic eruption of Laki, which produced a significant amount of sulfur in ash form to cover much of Europe (Stothers, 1996; Demarée et al., 1998). There also were significant floods throughout Europe in 1783 as evident in studies examining over 20 river systems (Brázdil et al., 2010b; 20 Glaser et al., 2010). If we examine the record just in Agricultural Records, we can see that the fog event is recorded, but there is no record of flooding as found in other sources (Stratton and Brown, 1978; Brázdil et al., 2010b). This could mean that it was overlooked by the editor or was not recorded or there was no flooding in England worthy to note. It is impossible to answer this question with just this document and 25 furhter proxy data would be needed.
7, 2555-2577, 2011

Content analysis for Agricultural Records

D. H. Holt
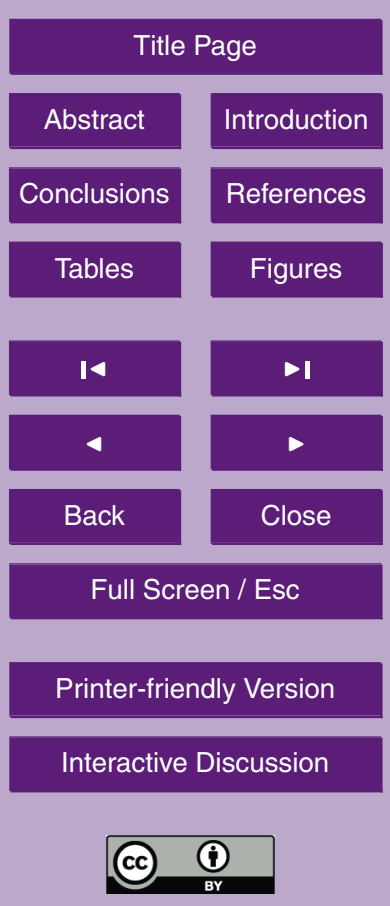


\section{Results}

The total number of years with records was 846 leaving a complement of 912 . The total number of codes for the 846 years was 4972 with a maximum of 21 , minimum of 1 , and a mean of 5.9 per year (Fig. 1). A continuous record of climate data begins in 1654 and 5 the data are divided at that point leaving three groupings: all records, records to 1653, and record from 1654 to 1977 . Another division was made for the LCO (950-1250) and the LIA (1450-1880) to see if this record reveals any patterns expected for these warmer or cooler periods.

The codes were factored as a percentage occurrence per year of record to analyze 10 which codes where considered significant enough to record. Looking to the full data set, the highest occurrence in the coding system is Good Harvest with $40.9 \%$ of the years covered. This is followed by Wet-Rainy, Storms-Windy, Cold-Frost, Bad-Late Harvest, and then Dry with all recording a coding occurrence of over $25 \%$ of year with records (Fig. 2). All of these categories have impact on the quality of harvest.

15 The lowest codes were Tide, Earthquake, Fog, Good Livestock, and Phenom with all recording less than $5 \%$ occurrence (Fig. 2). The Seasonal subcategory favored Summer at $44.09 \%$ with Fall being the lowest occurrence at $30.5 \%$ (Fig. 2).

The continuous record (AD 1654-1977) has different results in two ways: frequency and importance. The highest frequency occurrence was $71.91 \%$ with Wet-Rainy meaning the complement was only $28.09 \%$ of years had no record of wet or rainy conditions. This is followed by Storms-Windy, Cold-Frost, Dry, Mild-Fine-Warm, and Good Harvest with all above $50 \%$ occurrence (Fig. 2). The lowest codes were Earthquake, Famine, Plague Human, and Tide with all under $5 \%$ occurrence (Fig. 2). The Seasonal subcategory favored Summer with $85.49 \%$ with Year being the lowest at $45.68 \%$ occurrence (Fig. 2 ).

The discontinuous record (AD 220-1653) has a maximum occurrence of $31.99 \%$ in the code, Good Harvest. This is followed by Bad-Late Harvest, Wet-Rainy, Famine, and Storms-Windy with all at or above $15 \%$ occurrence (Fig. 2). The lowest codes were
$7,2555-2577,2011$

Content analysis for Agricultural Records

D. H. Holt
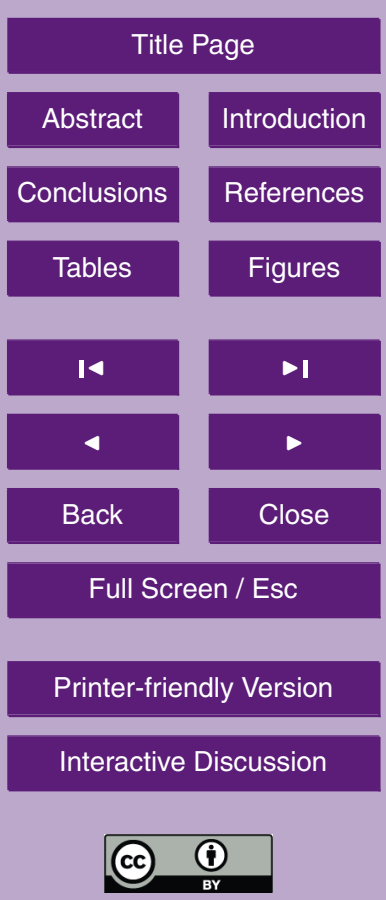
Fog, Sunny, Climate Record, Cool, and Cloudy with all under $1 \%$ occurrence (Fig. 2). The Seasonal subcategory favored Year with $26.82 \%$ with Fall being the lowest at $8.43 \%$ occurrence (Fig. 2).

Over this study period the seasonal references $(61.82 \%)$ gain importance over de5 scribing the entire year (34.04\%) all three groupings, especially in the continuous record. While it should be safe to presume that before 1653 there were sunny and foggy spells, it is not mentioned in this text until after 1654. Same presumption should hold true for the reduction in occurrence of famine or plague in the continuous record over the discontinuous record. A shift in the paradigm of importance to the documenter, 10 and possibly the editors, becomes apparent. In this text the focus of recording is not on solely negative aspects of climate.

The comparison between the LCO and the LIA show similarities in the dominant categories of percent occurrence. The five highest occurrences came in the codes: Famine, Storms-Windy, Wet-Rainy, Bad/Late Harvest, and Flood for the LCO and Good 15 Harvest, Wet-Rainy, Storms-Windy, Cold-Frost, and Bad/Late Harvest in the LIA. The codes, Hot, Warm and Harsh Winter, are not common in the LCO as they are in the LIA. The codes, Frozen Rivers and Flood, reveals little difference. Cold-Frost, Good Harvest, Dry, and Mild-Warm increased significantly from LCO to LIA (Fig. 3).

\section{Problems}

20 While this technique does show a change in significance in recorded events, it is potentially limited as it only uses one text and the text is edited. Does this content analysis reflect the documenter or editor in what is recorded or not recorded? This text was chosen with the knowledge that is a limitation but it does illustrate a change in focus. It is important to emphasize that this document uses many sources to compile the record, which meets the criteria of a good content analysis as it is a representative sample of all British documents, even though a review of all papers, etc. would be a more complete study. Another potential limitation on this study is that it is intended to focus

Content analysis for Agricultural Records

D. H. Holt

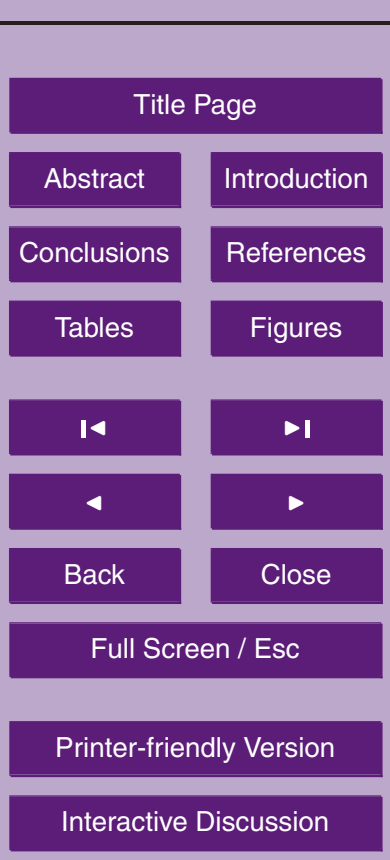


on agricultural productivity and crop prices. This is not considered too problematic because it is a bias that can be easily identified and changes in documentation will still be relevant.

\section{Discussion and conclusion}

5 Further research of different historical documents provides an insight into the psyche of the recorders of climate through content analysis. The systematic deconstruction of large texts for climate information may show how climate information may be slanted or skewed by the cultures' biases. A cultures' dialectic may help to understand the origin point of communication, which could help in turn with understanding why and how cultures write about and are concerned about climate and weather (Reinard, 1998).

The relationship between agriculture and climate change was surely understood in the past although it may have not been fully comprehended. The records of climate events that have found their way into the documentation suggests those poor climate times were felt deeply. However, any general analysis of weather effects on agriculture 15 is necessarily coarse-grained since each farming activity has its own particular environmental requirements. The weather which favors one crop at a particular stage of its growth may hinder the development of another (Flohn and Fantechi, 1984). This is definitely problematic when dealing with ancient cultures, where the documentation is usually incomplete.

20 But in Agricultural Records we can begin to understand what people record given the opportunity. If we look at the whole record, data concerning the season or year hold the highest importance with 1562 occurrences. This shows a need for temporal reference even in times before detailed chronographs, granted these references were seasonal, but even the very oldest references (e.g. AD 545 and 554) included seasonal references. The next big groupings have similar frequencies with precipitation events (1109 occurrences) and references to life as affected by climate (1075 occurrences). Events concerning the temperature (849 occurrences) are the fourth highest.

Content analysis for Agricultural Records

D. H. Holt

\section{Title Page}

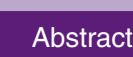

Introduction

Conclusions

References

Tables

Figures
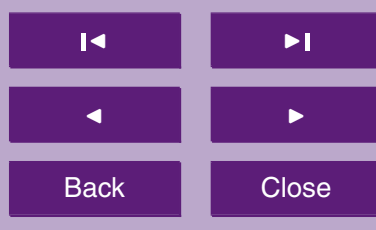

Back
Printer-friendly Version

Interactive Discussion 
The lowest groupings are various atmospheric phenomena (159 occurrences) and any other climate references (218 occurrences).

A good way to address which codes may have been the most significant is to look at the extremes in all three divisions (discontinuous, continuous, and total record) (Fig. 2).

5 If we look at Hot and Cold, there seems to be more importance in Cold. This changes with the moderate categories of Warm and Cool, with Warm being the favored code in all three divisions. The same could be seen with Wet over Dry and Good Harvest over Bad Harvest. Little difference is found between Sunny and Cloudy.

Among the codes that show significant changes between the three divisions are sea10 sons coding more than Year with Summer and Spring holding the highest occurrences. This may be a bias of the text with its focus on agricultural pricing. Logically, Climate Records increase greatly from the discontinuous record to the continuous record. Most codes increase in frequency in the continuous period with few exceptions (i.e. Human Plague, Famine, Tide). The most interesting portion of the continuous period is the im15 portance of recording events that code in Wet-Rainy and Storms-Windy, which occur in over $2 / 3$ of all years. The codes of Summer, Spring, and Winter occur in over 3/4 of all years (Fig. 2).

To reveal if there is a bias in human records, one needs to look at two periods that were markedly warmer (the LCO) and markedly cooler (the LIA). The Little Climate Optimum would expect an increase in the Warm and Hot codes and a decrease in Cold, Harsh Winter, Frozen Rivers, but there does not seem to be any trend that suggests this is the case (Fig. 2). The main codes of the LCO are Famine and Storms-Windy. Conversely, the Little Ice Age should code Cold-Frost, Harsh Winters, Cold Springs, Frozen Rivers more favorably than Hot or Sunny, but there does not seem anything out of the ordinary compared to the changes between the continuous and discontinuous periods. The main codes of the LIA are Good Harvest, Wet-Rainy, Storms-Windy, and Cold-Frost. While many reference the frozen rivers of the LIA, they do not show up too much in the record. Proxy evidence suggests the LIA was impacted by the North Atlantic Oscillation and some atmospheric component, which should have made
$7,2555-2577,2011$

Content analysis for Agricultural Records

D. H. Holt

Title Page

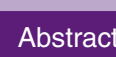

Introduction

Conclusions

References

Tables

Figures

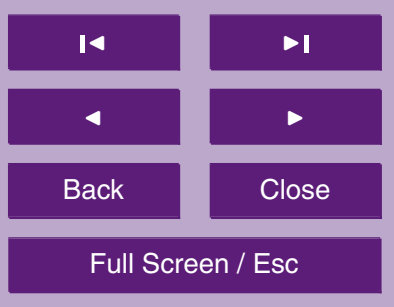

Printer-friendly Version

Interactive Discussion 
England much cooler (Palastanga et al., 2011), but this change is not recorded in this text. Further, the dominant code is referencing good harvests almost half of the years recorded. There does not seem to be a bias expected by these two, known climate periods. Granted neither the LCO was not warm every year nor the LIA cool every year, 5 but the main trends are not revealed in the record as evident in Agricultural Records. Perhaps the gradual change in climate in the LCO and LIA was too gradual to notice and record?

It appears that humans document the weather relatively consistently over time, without the presumed bias of "bad" weather in the records. There is a greater focus on 10 extremes in the early record and a greater focus on temporal references in the later record. While this study is using a book that is edited to show commodity prices and crop yields, it is including all references to climate in hopes to find a correlation. These references are well dated, so it is a useful source. The human record becomes much more detailed the closer to the meteorological period, but there does not seem to any 15 significant bias in what is recorded.

If we can understand what humans record when documenting the climate, we can better understand the documents. This could be useful to compare paleoclimate reconstructions of the time period to see if there is a correlation between the references and the proxy indicators as suggested by a few (Frenzel et al., 1992; Ogilvie, 2010) and as have been accomplished by other studies (Brázdil et al., 2010b; Zorita et al., 2010). Being that there is no apparent bias in the human documentation of climate in this study, records can be taken for face value and we should not presume to infer trends, even though human documents are not always accurate (Ogilvie, 2010). Perhaps other cultures have different priorities, but as for Agricultural Records from the UK there is little evidence to suggest that humans favor "good" or "bad" climate when documenting the weather.
7, 2555-2577, 2011

Content analysis for Agricultural Records

D. H. Holt

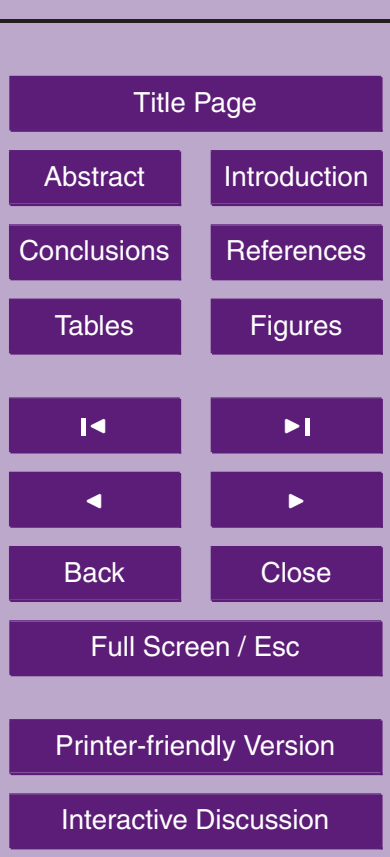




\section{References}

Baillie, M. G. L.: Marking in marker dates: towards an archaeology with historical precision, World Archaeol., 23(2), 233-243, 1995.

Baron, W. R.: The reconstruction of eighteenth century temperature records through the use of content analysis, Climatic Change, 4, 385-398, 1982.

Brázdil, R., Dobrovolný, P., Luterbacher, J., Moberg, A., Pfister, C., Wheeler, D., and Zorita, E: European climate of the past 500 years: new challenges for historical climatology, Climatic Change, 101(1/2), 7-40, 2010a.

Brázdil, R., Demarée, G., Deutsch, M., Garnier, E., Kiss, A., Luterbacher, J., Chromá, K. et al.: European floods during the winter 1783/1784: scenarios of an extreme event during the "Little Ice Age", Theor. Appl. Climatol., 100(1/2), 163-189, $2010 \mathrm{~b}$.

Briffa, K. R., Jones, P. D., and Schweingruber, F. H.: Summer temperature patterns over Europe: a reconstruction from 1750 A.D. based on maximum latewood density indices of conifers, Quaternary Res., 30, 36-52, 1988.

15 Catherine the Great: The Memoirs of Catherine the Great, edited by: Maroger, D., translated by: Budberg, M., The MacMillan Company, New York, 1955.

Chenoweth, M.: Ships' logbooks and the year without a summer, B. Am. Meteorol. Soc., 77(9), 2077-2093, 1996.

Demarée, G. R., Ogilvie, A. E. J., and Zhang, D.: Further Documentary Evidence of Northern Hemispheric Coverage of the Great Dry Fog of 1783, Climatic Change, 39(4), 727-730, 1998.

Dobrovolný, P., Moberg, A., Brázdil, R., Pfister, C., Glaser, R., Wilson, R., Böhm, R. et al.: Monthly, seasonal and annual temperature reconstructions for Central Europe derived from documentary evidence and instrumental records since AD 1500, Climatic Change, 101(1/2), 69-107, 2010.

Flohn, H. and Fantechi, R.: The climate of Europe: past, present and future: Natural and maninduced climatic changes: a European perspective, D. Reidel Publishing Company, Boston, 1984.

Frenzel, B., Pfister, C., and Gla"ser, B.: European climate reconstructed from documentary data: methods and results, G. Fischer, Stuttgart, 1992.

George, A. L.: Qualitative and quantitative procedures in content analysis, Rand Corporation, Santa Monica, California, 1954.
$7,2555-2577,2011$

\section{Content analysis for} Agricultural Records

D. H. Holt
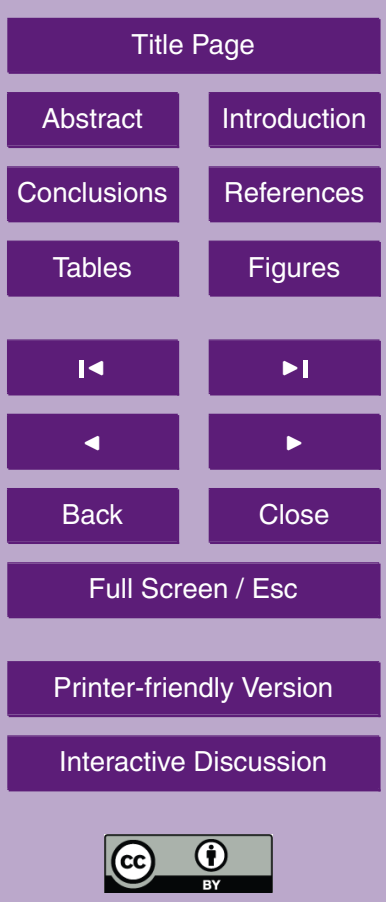
Glaser, R., Riemann, D., Schönbein, J., Barriendos, M., Brázdil, R., Bertolin, C., Himmelsbach, I. et al.: The variability of European floods since AD 1500, Climatic Change, 101(1/2), 235256, 2010.

Hodson, R.: Analyzing document accounts, Sage Publications, Thousand Oaks, California, 1999.

Holt, D. H.: Germania and Climate Variability in 3rd and 4th Centuries A.D.: A Methodological Approach to Dendroclimatology and Human Migration, Phys. Geogr., 32(3), 241-268, 2011.

Le Roy Ladurie, E.: Times of feast, times of famine: a history of climate since the year 1000 , Farrar Struas and Giroux, New York, 1988.

10 Ménétra, J.-L.: Journal of My Life, translated by: Goldhammer, A., Columbia University Press, New York, 1984.

Migalina, S. V., Ivanova, L. A., and Makhnev, A. K.: Size of the leaf as a marker of birch productivity at a distance from the climatic optimum, Russ. J. Plant Physiol., 56(6), 858-862, 2009.

Ogilvie, A. E. J.: Historical climatology, Climatic Change, and implications for climate science in the twenty-first century, Climatic Change, 100(1), 33-47, 2010.

Ogilvie, A. E. J. and Jonsdottir, I. I.: Sea ice, climate, and Icelandic fisheries in the eighteenth and nineteenth centuries, Arctic, 53(4), 383, 2000.

Palastanga, V., van der Schrier, G., Weber, S., Kleinen, T., Briffa, K., and Osborn, T.: Atmosphere and ocean dynamics: contributors to the European Little Ice Age?, Clim. Dynam., 36(5/6), 973-987, 2011.

Parry, M. L.: Climate change and the agricultural frontier, in: Climate and History: Studies in Past Climate and their Impact on Man, edited by: Wigley, T. M. L. and Ingram, M. J., Cambridge Univeristy Press, Cambridge, 1981.

Pfister, C.: The vulnerability of past societies to climatic variation: a new focus for historical climatology in the twenty-first century, Climatic Change, 100(1), 25-31, 2010.

Reece, R.: The later Roman Empire: an archaeology AD 150-600, Tempus Publishing Group, Brussels, Belgium, 1999.

Reinard, J.: Introduction to communication research, McGraw Hill, New York, 1998.

30 Reiter, P.: From Shakespeare to Defoe: Malaria in England in the Little Ice Age, Emerg. Infect. Dis., 6(1), 1-11, 2000.

Stothers, R. B.: The Great Dry Fog of 1783, Climatic Change, 32, 79-89, 1996.
$7,2555-2577,2011$

\section{Content analysis for}

Agricultural Records

D. H. Holt

\section{Title Page}

Abstract

Introduction

Conclusions

References

Tables

Figures

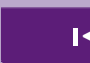

14

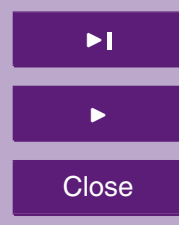

Back

Full Screen / Esc

Printer-friendly Version

Interactive Discussion

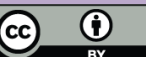


Stratton, J. M. and Brown, J. H.: Agricultural records in Britain: AD 220-1977, Archon Books, Hamden, Conneticut, 1978.

Toke, N. and Lodge, E. C.: The account book of a kentish estate, 1616-1704, Oxford University Press, London, 1927.

5 Wigley, T. M. L., Ingram, M. J., and Farmer, G.: Climate and history: studies in past climates and their impact on man, Cambridge University Press, New York, 1981.

Zorita, E., Morberg, A., Leijonhufvud, L., Wilson, R., Brázdil, R., Dobrovolny, P., GonzalezRouco, F. et al.: European temperature records of the past five centuries based on documentary/instrumental information compared to climate simulations, Climatic Change, 101(1/2), 143-168, 2010.

Content analysis for Agricultural Records

D. H. Holt

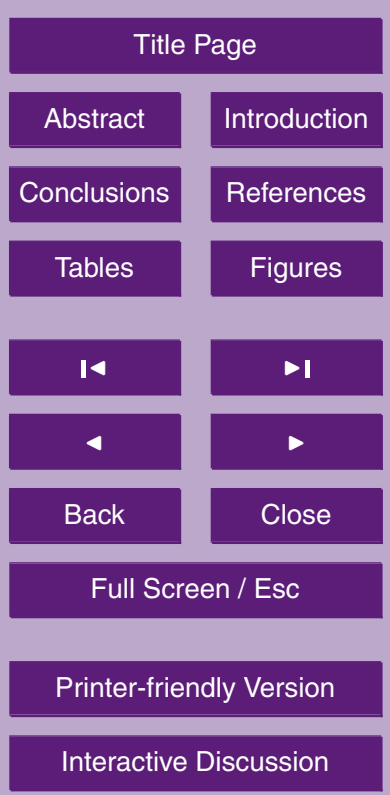




\section{Histogram of Agricultural Records}

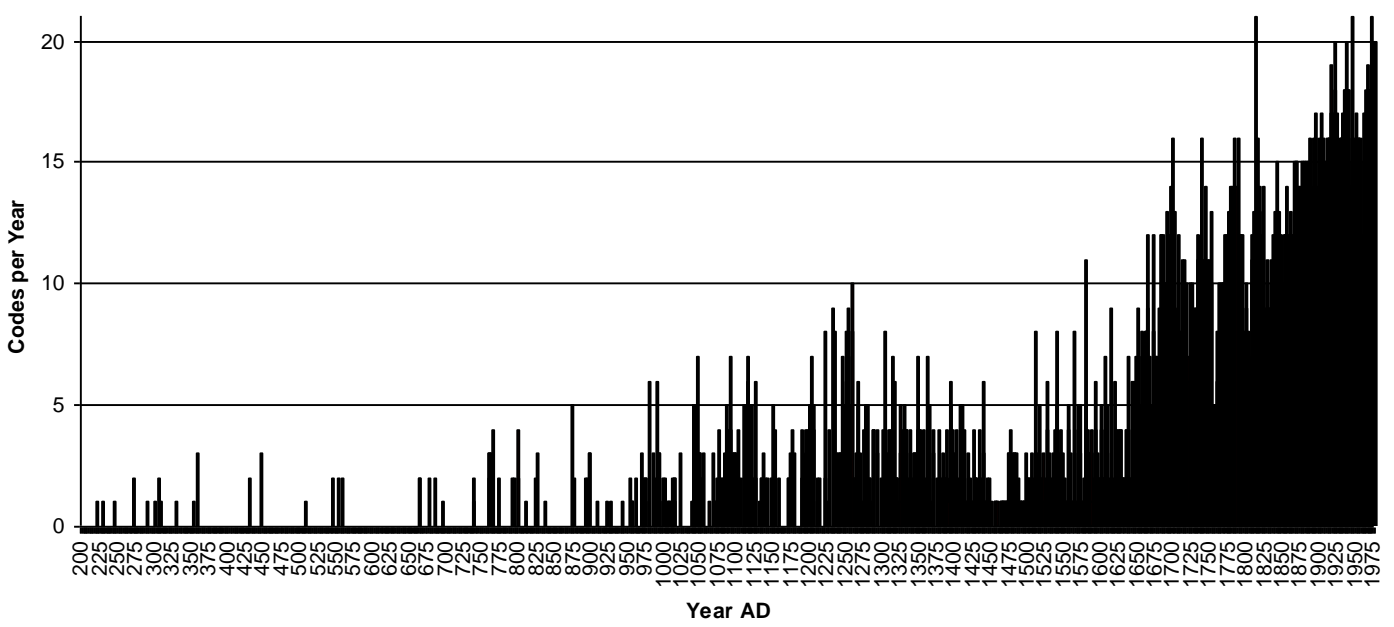

Fig. 1. Chart showing the number of coded events by year from AD 200 to 1977 in the content analysis of documented climate in the UK.
$7,2555-2577,2011$

\section{Content analysis for} Agricultural Records

D. H. Holt

\section{Title Page}

\begin{tabular}{c|c}
\hline Abstract & Introduction \\
\hline Conclusions & References \\
\hline Tables & Figures \\
\hline I4 & $\triangleright$ I \\
\hline 4 & $\triangleright$ \\
\hline Back & Close \\
\hline Full Screen / Esc
\end{tabular}

Printer-friendly Version

Interactive Discussion

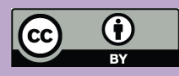




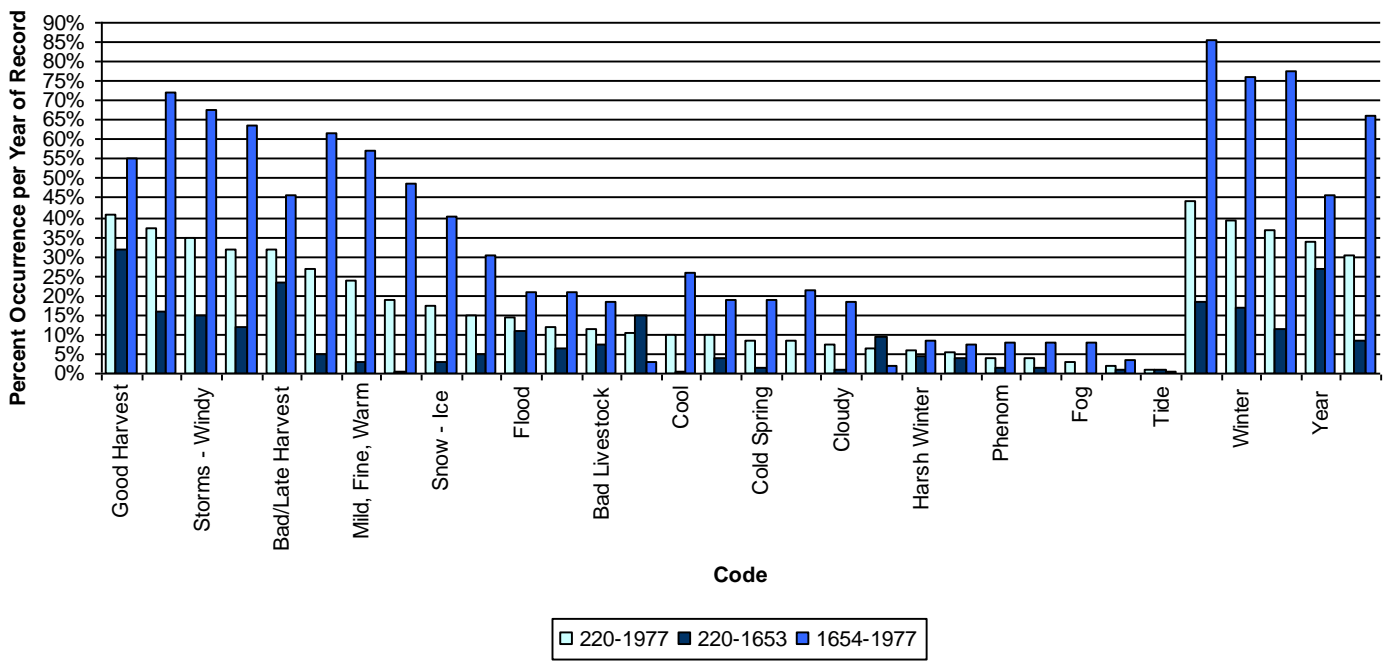

\section{Content analysis for} Agricultural Records

D. H. Holt

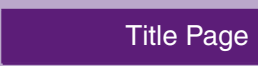

\begin{tabular}{cc|}
\hline Abstract & Introduction \\
\hline Conclusions & References \\
\hline Tables & Figures \\
\hline I4 & - I \\
\hline 4 & $>$ \\
\hline Back & Close \\
\hline Full Screen / Esc
\end{tabular}

Fig. 2. Chart showing the percent occurrence per year of written record in the whole record, continuous record, and discontinuous record. Unrecorded years in the discontinuous record did not count in percentage occurrence.

Printer-friendly Version

Interactive Discussion

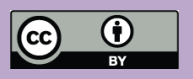


Coding Frequencies in Years of Record For Little Climate Optimum (LCO) and Little Ice Age (LIA)

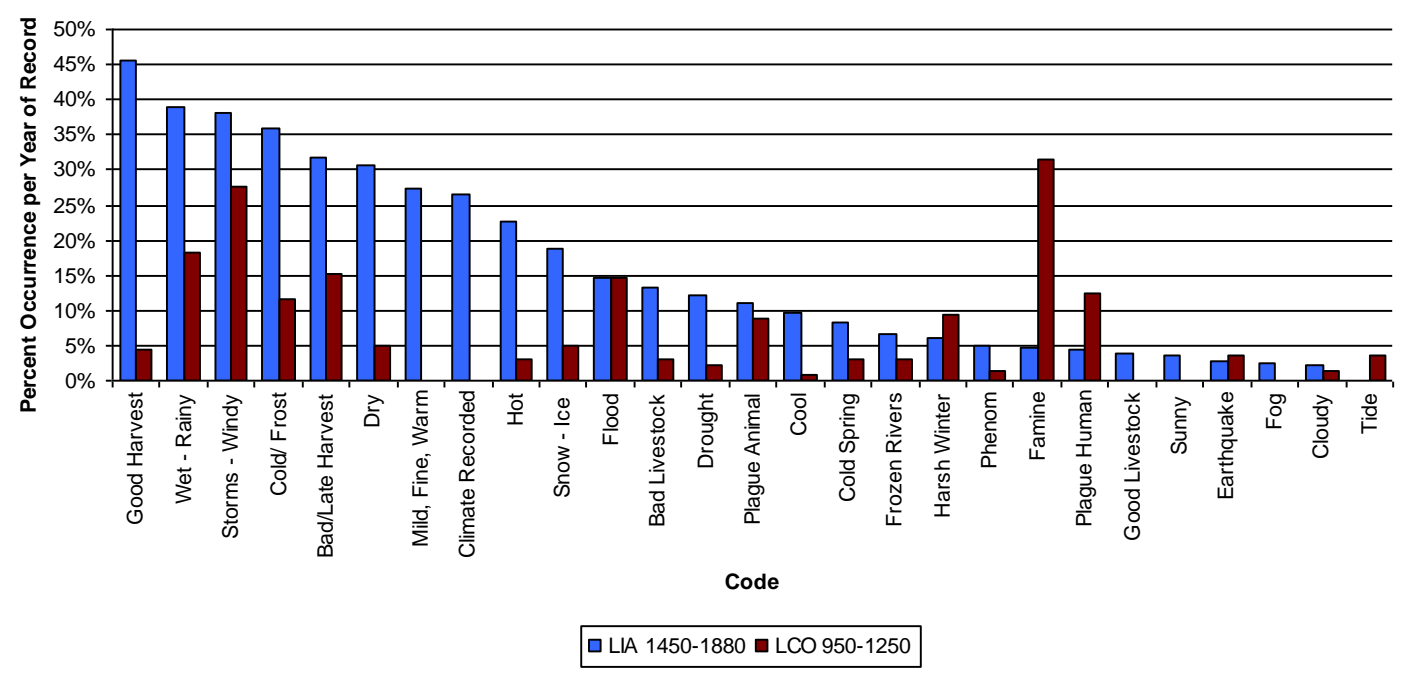

Fig. 3. Chart showing the percent occurrence per year of written record in the Little Climate Optimum (LCO) and Little Ice Age (LIA) to illustrate what is getting recorded in this warmer and cooler period. Unrecorded years did not count in percentage occurrence.

\section{Content analysis for} Agricultural Records

D. H. Holt

\begin{tabular}{|c|c|}
\hline \multicolumn{2}{|c|}{ Title Page } \\
\hline Abstract & Introduction \\
\hline Conclusions & References \\
\hline Tables & Figures \\
\hline I4 & \\
\hline 4 & $-\mathbf{I}$ \\
\hline Back & Close \\
\hline Full Screen / Esc
\end{tabular}

Printer-friendly Version

Interactive Discussion 